\title{
Partial Hydatidiform Mole in an Ectopic Tubal Pregnancy
}

\author{
Abdulkarim Hasan ${ }^{1}$, Ahmed Elhawary ${ }^{2}$, Mohamed F. Abdelaleem ${ }^{3}$, Tarek Hegazy ${ }^{4}$, Khalid M. Nafie ${ }^{5}$ \\ 1. Pathology, Faculty of Medicine, Al-Azhar University, Cairo, EGY 2. Primary Health Care Centers, Ministry of Health, \\ Taba, EGY 3. Primary Health Care Centers, Ministry of Health, Cairo, EGY 4. Obstetrics and Gynaecology, Ministry of \\ Health, Tanta, EGY 5. Laboratory and Blood Bank, Prince Mishari Bin Saud Hospital, Ministry of Health, Baljurashi, \\ SAU
}

Corresponding author: Abdulkarim Hasan, doctorabdulkarim7@gmail.com

\begin{abstract}
Fallopian tubal molar pregnancy is extremely rare, and the main diagnostic tool is the post-operative histopathological diagnosis, as the pre-operative diagnosis is difficult. We report a case of ectopic partial molar pregnancy in the right fallopian tube of a 35-year-old lady that was sent for routine histopathological examination with the clinical diagnosis of ectopic pregnancy and the histopathology report revealed an unusual result.
\end{abstract}

Categories: Obstetrics/Gynecology, Pathology

Keywords: ruptured ectopic pregnancy, histopathology examination, hydatidi form moles, fallopian tubes, surgical acute abdomen

\section{Introduction}

Gestational trophoblastic diseases (GTDs) consist of placental site trophoblastic tumor, choriocarcinoma, epithelioid trophoblastic tumor, and hydatidiform mole. The majority of GTDs occur in the uterus, but ectopic molar pregnancy is extremely rare (ectopic GTD incidence is 1.5 per one million births in the UK) [1]. There are two types of molar pregnancy: partial and complete moles. The partial molar pregnancy may be associated with a fetus [2]. The diagnosis of molar pregnancy at ectopic sites is very difficult as there is no distinguishing clinical feature but depends mainly on the pathology and DNA ploidy analysis [3]. Although molar pregnancy and ectopic pregnancy are not rare events, the combination of the two, an ectopic molar pregnancy, is an extremely rare event [4]. Here, we present a case of tubal partial hydatidiform mole that was treated with salpingectomy and accidentally discovered during the histopathological examination, and the case possessed a favorable prognosis.

Review began 05/24/2021 Review ended 05/27/2021 Published 06/05/2021

\section{๑) Copyright 2021}

Hasan et al. This is an open access article distributed under the terms of the Creative Commons Attribution License CC-BY 4.0., which permits unrestricted use, distribution, and reproduction in any medium, provided the original author and source are credited.

\section{Case Presentation}

A 35-year-old female came to the primary care center complaining of acute lower abdominal pain with a history of amenorrhea for two months and spotting per vaginum. Upon presentation, the abdominal pain was of sudden onset, not radiating, continuous, and not relieved by oral analgesics. There was no history of vomiting or fever. Her blood pressure (arterial blood pressure, ABP) was 105/75 $\mathrm{mmHg}$, with a pulse of 70 beats/minute. Clinical examination revealed a soft abdomen and mild tenderness in the right iliac fossa.

A pregnancy test was requested and revealed a positive result with elevated human chorionic gonadotropin $\beta$ ( $\beta$-hCG) titer (30000 units $/ \mathrm{mL}$ ). The patient was referred to the obstetric department at the referral hospital, in which she reported an obstetric score of gravida 3 para 2a with normal past obstetric history. Per vaginal examination revealed right cervical tenderness. Pelvic ultrasonography showed a $4.5 \mathrm{~cm} \times 3 \mathrm{~cm}$ swelling adjacent to the right ovary with a gestational sac containing a viable gestational sac with active heartbeats and body motions, a gestational age of 10 weeks, and a uterus within the normal size. Hemoglobin level was $10.5 \mathrm{~g} / \mathrm{dL}$, other routine hematology and biochemistry examinations were within normal ranges.

The patient was primarily diagnosed clinically with ruptured ectopic pregnancy. Explorative laparoscopy was performed and a ruptured mass was detected in the ampulla of the right fallopian tube. A little free fluid collection in the Douglas pouch was also seen. Right salpingectomy was performed and sent to the histopathology laboratory in a formalin fixative fluid.

Grossly, the content of the fallopian tube consisted of a lump of blood clots in which edematous-looking villi and fetal tissue measuring $4.5 \mathrm{~cm}$ were seen. Upon microscopic examination by the senior pathologists, polar proliferated syncytiotrophoblastic and cytotrophoblastic cells were noted with irregular shape and edematous stroma with fetal tissue. The hydropic appearance was mild to moderate. Histological features are consistent with a non-invasive molar pregnancy, the complete mole was excluded due to the presence of fetal parts, the patient was advised for karyotype analysis, and the final diagnosis was confirmed as a partial hydatidiform molar pregnancy. Follow-up with $\beta$-hCG serum level was done and a gradual decline of the 


\section{Cureus}

hormone level was recorded without noted complications (Figures 1-2).

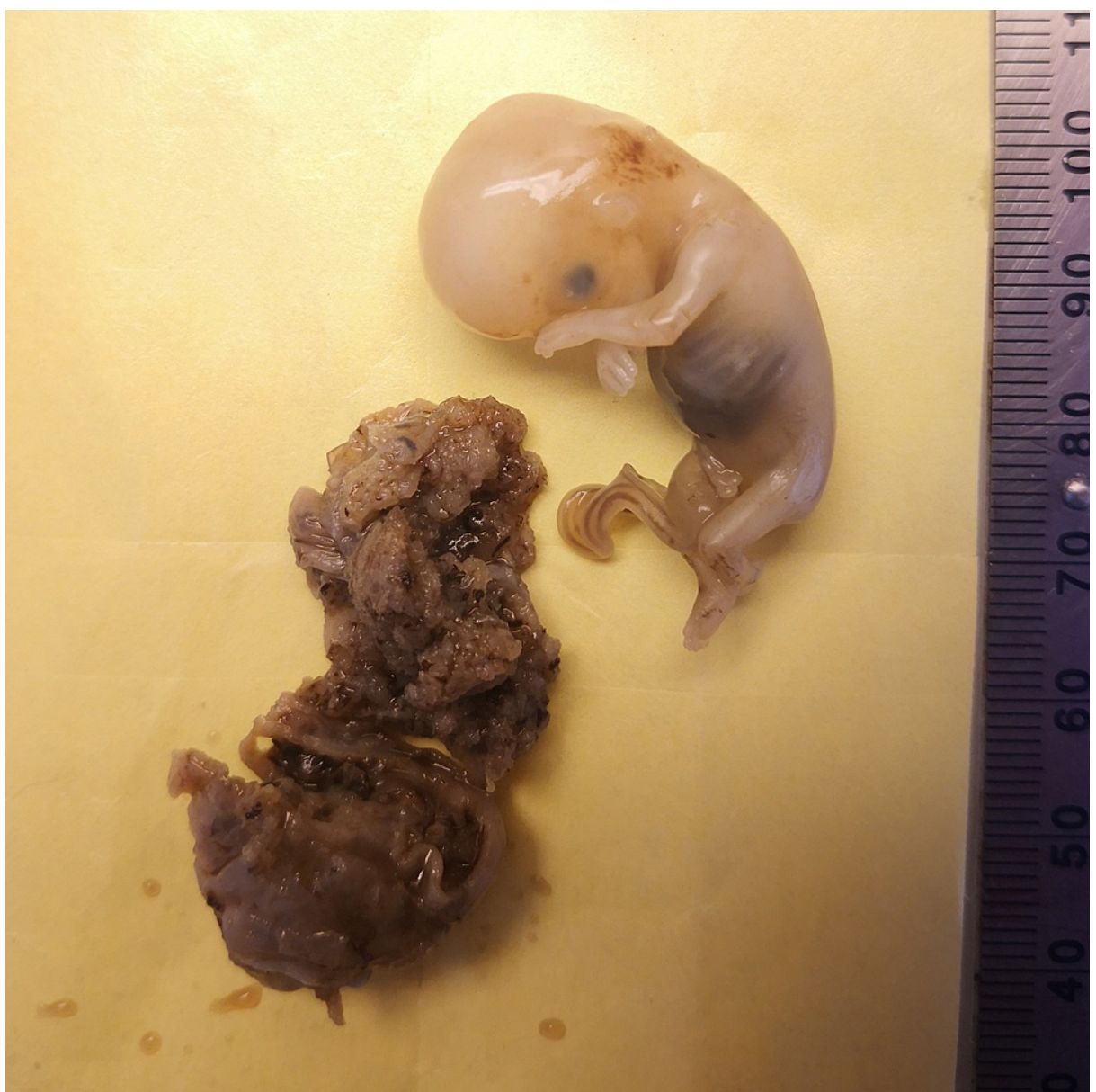

FIGURE 1: Gross picture.

A gross picture showing ruptured fallopian tube, blood clots, small vesicles, and fetal tissue 


\section{Cureus}

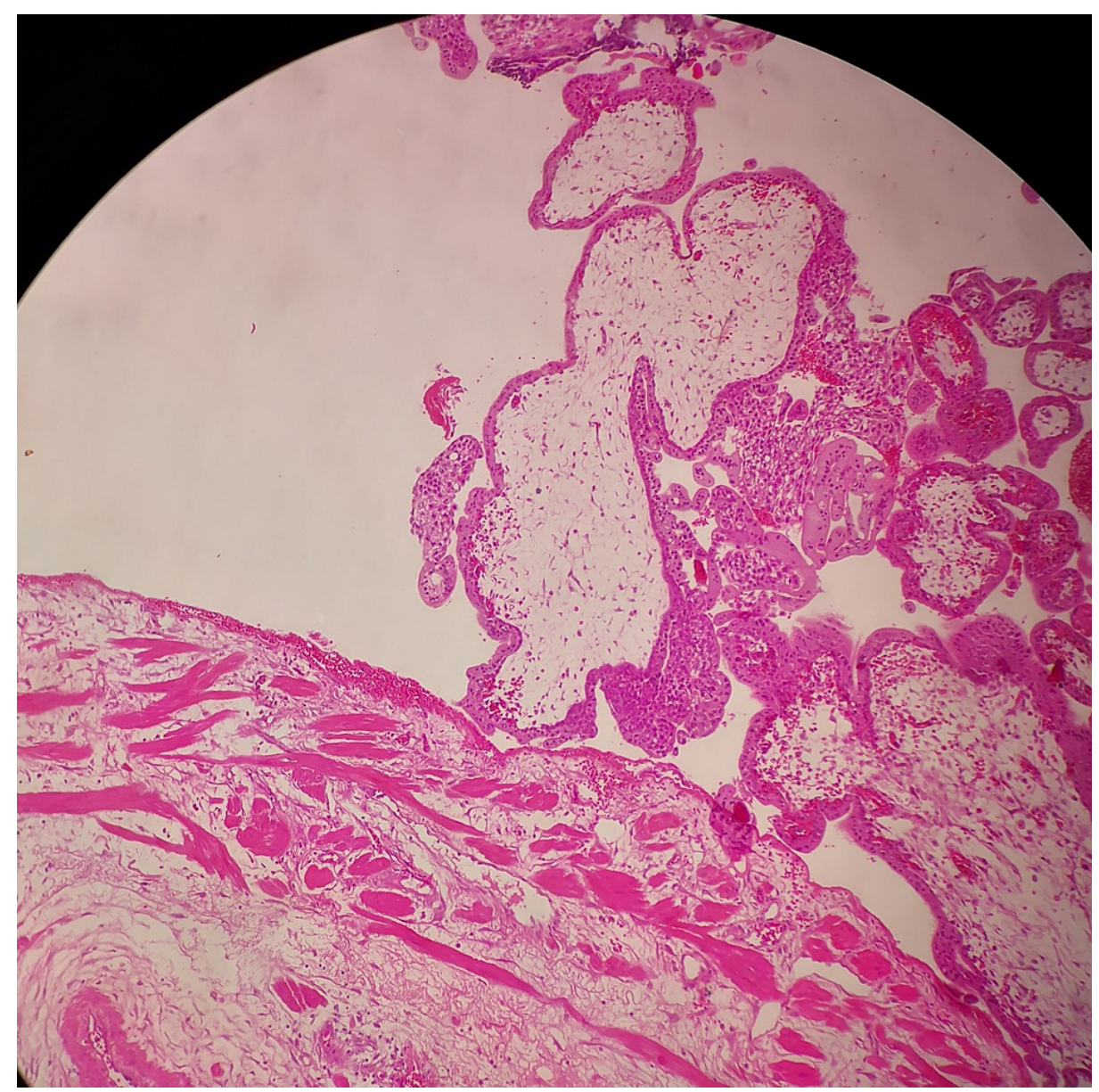

FIGURE 2: Microscopic picture.

A microscopic picture showing edematous villi along with villi with polar trophoblastic proliferation attached to the wall (200x, H\&E).

\section{Discussion}

Tubal molar pregnancy is an extremely rare event. The incidence of the disease is estimated to be 1 $5 / 200,000$ which considerably varied in different countries [5].

The diagnosis of this disease and several other rare gynecological and obstetrician diseases depends mainly on histopathology studies, however, it is difficult histologically to be distinguished as molar from non-molar hydropic changes [6-9].

Hydatidiform molar pregnancy is characterized by hydropic degeneration of chorionic villi associated with the proliferation of trophoblasts due to fertilization of the abnormal ovum. In complete mole, the genome is entirely made of paternal origin, due to fertilization of an empty ovum by a haploid sperm followed by chromosomal duplication or by fertilization by diploid sperm. Partial hydatidiform mole is a pathological process due to fertilization of the ovum by two sperms making a paternal to maternal chromosome ratio of $2: 1$ [10]. There was no reported definite risk factor for ectopic molar pregnancy owing to the scarcity of the disease, however, there are many suggested risk factors for abnormal pregnancies including pelvic inflammatory disease, intrauterine contraceptive devices, tubal surgery, and a previous ectopic pregnancy [11].

Clinically tubal molar pregnancies are usually indistinguishable from non-molar ectopic pregnancies. $\beta$-hCG levels are also not useful in differentiation [5, 12]. All surgically removed ectopic pregnancies depend on histopathological examination to specify or exclude molar change. Molar should be distinguished by the non-molar pregnancy as the former can cause a persistent trophoblastic disease or even metastasis to distant organs. Hence close follow-up is essential after the removal of products [4]. In difficult cases, the DNA flow cytometry for ploidy examination and P57 immunocytochemical staining is useful for differentiating partial from complete mole [13]. In our case, the microscopic features are inconsistent with the complete hydatidiform mole due to the presence of the fetal parts. 
During the histopathological examination, pathologists should keep in their minds that, compared with evacuated intra-uterine products of conception, the degree of extravillous trophoblastic proliferation might appear more florid in the ectopic gestation [7, 13]. Laparoscopy is the main way for the treatment of ectopic pregnancy cases. Pasic et al. have suggested that surgical treatment for the majority of patients should be salpingotomy in case of lack of rupture [14]. Our case was a ruptured tube at the time of diagnosis that is why the salpingectomy was the treatment of choice.

\section{Conclusions}

However, it is a very rare occurrence; ectopic molar pregnancy should be considered as a possibility in women presenting clinically with a suspected ectopic pregnancy. The histopathological examination of the salpingectomy specimen and conceptus in tubal pregnancies is essential for accurate diagnosis and appropriate follow-up management and histopathologist doctors should keep in minds the rare occurrence of molar proliferation in ectopic tubal pregnancies.

\section{Additional Information \\ Disclosures}

Human subjects: Consent was obtained or waived by all participants in this study. Conflicts of interest: In compliance with the ICMJE uniform disclosure form, all authors declare the following: Payment/services info: All authors have declared that no financial support was received from any organization for the submitted work. Financial relationships: All authors have declared that they have no financial relationships at present or within the previous three years with any organizations that might have an interest in the submitted work. Other relationships: All authors have declared that there are no other relationships or activities that could appear to have influenced the submitted work.

\section{References}

1. Yamada Y, Ohira S, Yamazaki T, Shiozawa T: Ectopic molar pregnancy: diagnostic efficacy of magnetic resonance imaging and review of the literature. Case Rep Obstet Gynecol. 2016, 2016:7618631. 10.1155/2016/7618631

2. Berkowitz RS, Goldstein DP, Bernstein MR: Natural history of partial molar pregnancy. Obstet Gynecol. 1985, 1:677-681.

3. Patil N, Nazeer RM, Tele J: Ectopic tubal pregnancy with partial mole: a rare case . Int J Reprod Contracept Obstet Gynecol. 2008, 7:1652. 10.18203/2320-1770.ijrcog20181374

4. Allen L, Dawson C, Nascu P, Rouse T: A molar pregnancy within the fallopian tube . Case Rep Obstet Gynecol. 2016, 2016:4367181. 10.1155/2016/4367181

5. Siozos A, Sriemevan A: A case of true tubal hydatidiform mole and literature review . BMJ Case Rep. 2010, 2010:bcr0720092123. 10.1136/bcr.07.2009.2123

6. Hasan A, Nafie K, Monazea K, Othman A, Salem A, Ismail A: A rare case of recurrent eccrine poroma underlying gluteal abscess. Int J Surg Case Rep. 2020, 75:29-31. 10.1016/j.ijscr.2020.08.042

7. Zhao T, Hou X, Su C, Wu Q: Tubal hydatidiform mole treated with salpingotomy: a case report . Clin Case Rep. 2019, 7:653-655. 10.1002/ccr3.2037

8. Hasan A, Abozied H, Youssef A, Fayad S, Ismail A: A rare case of collecting duct carcinoma with first presentation of respiratory symptoms. Urol Case Rep. 2020, 33:101367. 10.1016/j.eucr.2020.101367

9. Hasan A, Nafie K, Aldossary MY, et al.: Unexpected histopathology results following routine examination of cholecystectomy specimens: how big and how significant?. Ann Med Surg (Lond). 2020, 60:425-430. 10.1016/j.amsu.2020.11.019

10. Burton JL, Lidbury EA, Gillespie AM, et al.: Over-diagnosis of hydatidiform mole in early tubal ectopic pregnancy. Histopathology. 2001, 38:409-417. 10.1046/j.1365-2559.2001.01151.x

11. Tabandeh A, Besharat M: Fever after cervical ectopic pregnancy; a case report from Gorgan, Iran . Electron Phys. 2014, 6:944-946

12. Gari R, Abdulgader R, Abdulqader O: A live 13 weeks ruptured ectopic pregnancy: a case report . Cureus. 2020, 12:e10993. 10.7759/cureus.10993

13. Sebire NJ, Makrydimas G, Agnantis NJ, Zagorianakou N, Rees H, Fisher RA: Updated diagnostic criteria for partial and complete hydatidiform mole in early pregnancy. Anti-cancer Res. 2003, 23:1723-1728.

14. Pasic RP, Hammons G, Gardner JS, Hainer M: Laparoscopic treatment of cornual heterotopic pregnancy. J Am Assoc Gynecol Laparosc. 2000, 9:372-375. 